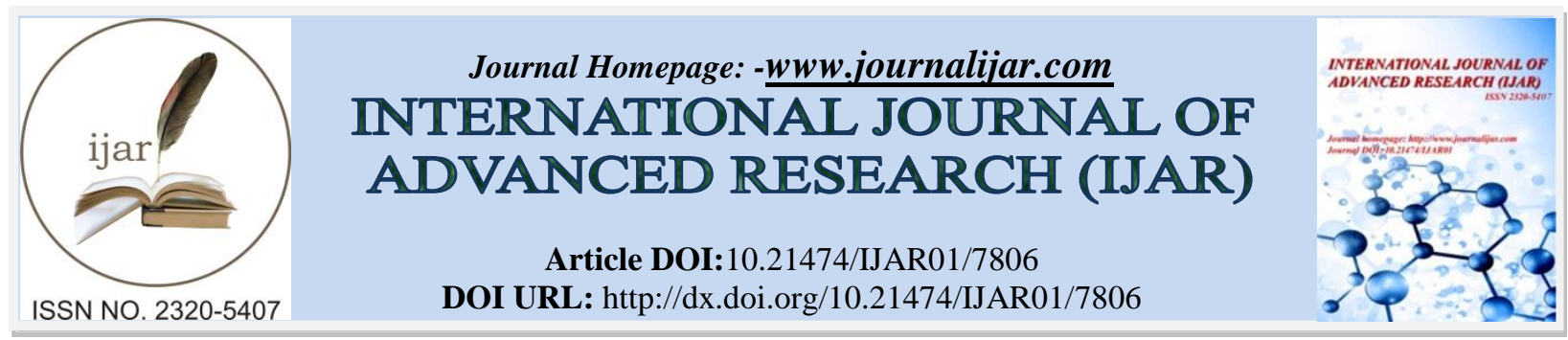

RESEARCH ARTICLE

\title{
A STUDY CONDUCTED FOR THE DETECTION OF HEPATITIS B VIRUS SEROPREVALANCE AND ASSOCIATED RISK FACTORS IN A TEACHING HOSPITAL MYSURU KARNATAKA.
}

Dr. Deepak kumar and Dr. Samreen Khan.

Dept of microbiology Jss medical college mysuru Karnataka.

\section{Manuscript Info}

Manuscript History

Received: 5 August 2018

Final Accepted: 7 September 2018

Published: October 2018

\section{Abstract}

Objectives and Aim:We performed a study on Seroprevelance of HBVandassociated risk factors among the patients attending a tertiary care hospital in India.

Background:Globally,Hepatitis $B$ is one of the most common infectious diseases. It is ranked by the WHO as one of the top ten killers. The virus is responsible for approximately 1.5 million deaths worldwide in each year, two thirds of which are attributable to primary Hepatocellular carcinoma following HBV infection. About 360 million people are estimated to be chronically infected with HBV.

Method --284 samples were positive for HBsAg by ELISA.

Results-The seroprevalence of Hepatitis B infection in our study was $6 \%$, associated with blood transfusion as the major risk factor.

Copy Right, IJAR, 2018,. All rights reserved.

\section{Introduction:-}

Viral hepatitis due to Hepatitis B virus (HBV) is a major public health problem throughout the world affecting several hundreds of millions of people. It is a cause of considerable morbidity and mortality in human population from both acute infections and chronic squeal which include acute infection, chronic active hepatitis, cirrhosis and primary liver cancer. ${ }^{1}$

Hepatitis B virus was recognized originally as the cause of serum hepatitis, the most common form of parenterally transmitted viral hepatitis, and an important cause of acute and chronic infection of the liver in many countries. More than one third of the world's population has been infected with HBV and WHO estimates that it results in 1 to 2 million deaths every year. The incubation period of hepatitis B is variable with a range of between 1 and 6 months. Acute hepatitis B infection is anicteric and asymptomatic most of the time, although a severe illness with jaundice can occur and acute liver failure may develop. The virus persists in about $10 \%$ of infected immunocompetent adults and in as many as $90 \%$ of infants infected perinatally,depending on the ethnic group of the mother.About 350 million people worldwide are persistent carriers of HBV.Liver damage is mediated by the cellular immune response of the host to the infected hepatocytes.Approximately $25 \%$ of all patients with chronic hepatitis will progress to cirrhosis and about $20 \%$ of those with cirrhosis will develop Hepatocellular carcinoma. ${ }^{2}$

Hepatocellular Carcinoma is one of the most common cancers worldwide. However the significance and magnitude of the problem vary from country to country. ${ }^{3}$ 
As per WHO guidelines, Countries are classified on the basis of endemicity of hepatitis-B virus (HBV) infection into high $(8 \%$ or more), intermediate $(2-7 \%)$, or low (less than $2 \%$ ) incidence countries. The prevalence of chronic $\mathrm{HBV}$ infection in India ranges from $2 \%$ to $10 \%$ as shown in different studies. India therefore comes under the intermediate to high endemicity category. India hasapproximately HBV carrier rate of $3.0 \%$ with a high prevalence rate in the tribal population. ${ }^{3}$ With a populationof more than 1.25 billion, India has more than 37 million HBV carriers and contributes a large proportion of the globalHBV burden. While horizontal transmission in childhood appears to be a major route of transmission, the roleof vertical transmission is probably underestimated ${ }^{4}$. Blood transfusion and unsafe therapeutic injections continue to be important modes of transmission of HBV., ${ }^{3,4,5}$

\section{Material and Methods:-}

\section{Source of data}

Total number of samples received during the study period of one year in the Department of Microbiology, JSS Hospital, Mysuru for HBV screening were 4648 out of which HBsAg was detected in 284 (6.2\%) by ELISA.

\section{Inclusion Criteria}

1. All patients suspected of Hepatitis and in whom HBsAg is detected by ELISA

2. Asymptomatic patients for whom serum samples are submitted to the laboratory for routine investigation and are HBsAg positive, in spite of the clinical presentation.

\section{Exclusion Criteria}

Patients who are treated with Antiviral therapy are excluded from the study

\section{Collection of samples}

$2 \mathrm{ml}$ of venous blood sample was collected in EDTA vacutainer from patients who tested positive for anti HBV antibody by $3^{\text {rd }}$ generation ELISA (QUALISA).

Demographic data and clinical history and clinical examination of the patients who were seropositive was recorded in the proforma and risk factors for the infection were taken note of, haematological tests (PT, Platelet count) and liver function tests(LFT) were done for these patients. Liver biopsy, ultrasonography, CT abdomen and fibroscan were also done for these patients.

\section{Tables and Figures}

\section{Cross Sectional Study}

Cross sectional study is the simplest form of an observational study. It is based on a single examination of a crosssection of population at one point in time- the results of which can be projected on the whole population provided the sampling has been done correctly. Cross sectional study is also known as "prevalence study". Cross-sectional studies are more useful for chronic diseases. It tells about the distribution of a disease in population rather than its aetiology.

\section{Statistical Methods Applied}

Qualitative variables are expressed as proportions and 95\% confidence interval (95\% CI). Quantitative variables are expressed as mean and standard deviation. Chi square test is used to check the association of qualitative variables.

In accordance with the prevalence of seropositivity the same number of controls were randomly selected and analysis done for association with risk factors using chi square test.

\section{Contingency coefficient test (Cross tabs)}

The Crosstabs procedure forms two-way and multiway tables and provides a variety of tests and measures of association for two-way tables. The structure of the table and whether categories are ordered determine what test or measure to use.

\section{Chi-square test}

The Chi-Square Test procedure tabulates a variable into categories and computes a chi-square statistic. This goodness-of-fit test compares the observed and expected frequencies in eachcategory to test either that all categories contain the same proportion of values or that each category contains a user-specified proportion of values.

All the statistical methods were carried out through the SPSS for Windows (version 16.0). 


\section{Results:-}

Demographic characteristics

Out of 4648 serum samples submitted to the Department of Microbiology at JSS Hospital Mysuru during the study period of one year, 284 samples were positive for HBsAg by ELISA (Figure 1).The patients for whom the samples were submitted formed the subjects of this study. Out of these 198 were Male (69.7\%) and 86 were female (30.3\%) (Table 2, Graph 3).The mean age of the patients was $39.426 \pm 10.6$ years.(Table 1, Graph 2). Majority of the samples for evaluation of the HBV infection were from the Department of Medicine (145/284[51.5\%]), followed by Department of Surgery,OBG,Nephrology, Skin and from Dental also. (Table 3, Graph 4). The most predominant risk factors of HBV acquisition in our study was Blood transfusion (101/284[35.6\%]), followed by tattooing $(36 / 284[12.7 \%])$ and $(34 / 284[12.0 \%])$ patients had genital ulcers leading to a probable association with sexual transmission and exposure to major and minor surgical procedure i.e., abscess drainage (I and D) were found in [16/284(5.6\%)] patients and oral /dental implant in (16/284[5.6\%]). Other associated risk factors were Haemodialysis (12/284[4.2\%]),Ear piercing (11/284[3.9\%]), Nose piercing (10/284[3.5\%]), while in (48/284[16.9\%]) no specific history was elicitable.(Table 4, Graph 5).

Figure 1:-Prevalence of HBV

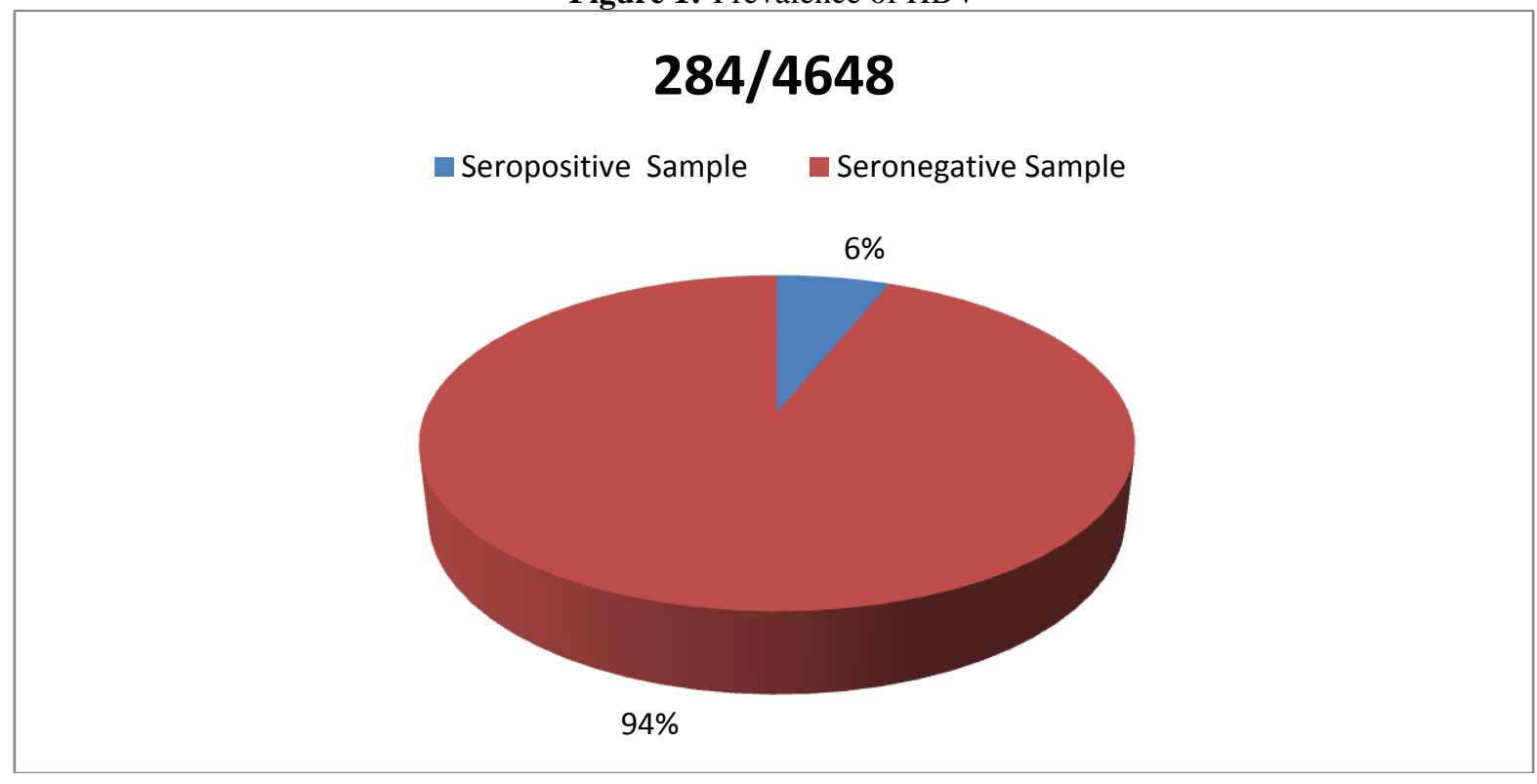

Demographic distribution

Table 1:-Age distribution

\begin{tabular}{|l|c|c|}
\hline AGE & FREQUENCY & PERCENTAGE \\
\hline $0-10$ YEARS & - & - \\
\hline $11-20$ YEARS & 9 & 3.2 \\
\hline $21-30$ YEARS & 63 & 22.2 \\
\hline $31-40$ YEARS & 109 & 38.4 \\
\hline $41-50$ YEARS & 66 & 23.2 \\
\hline $51-60$ YEARS & 29 & 10.2 \\
\hline 61-70YEARS & 8 & 2.8 \\
\hline TOTAL & 284 & 100 \\
\hline
\end{tabular}

MEAN $=39.426$

$\mathrm{SD}=10.6$

MINIMUM $=16.0$

MAXIMUM=70.0 
figure 2:-Age distribution.

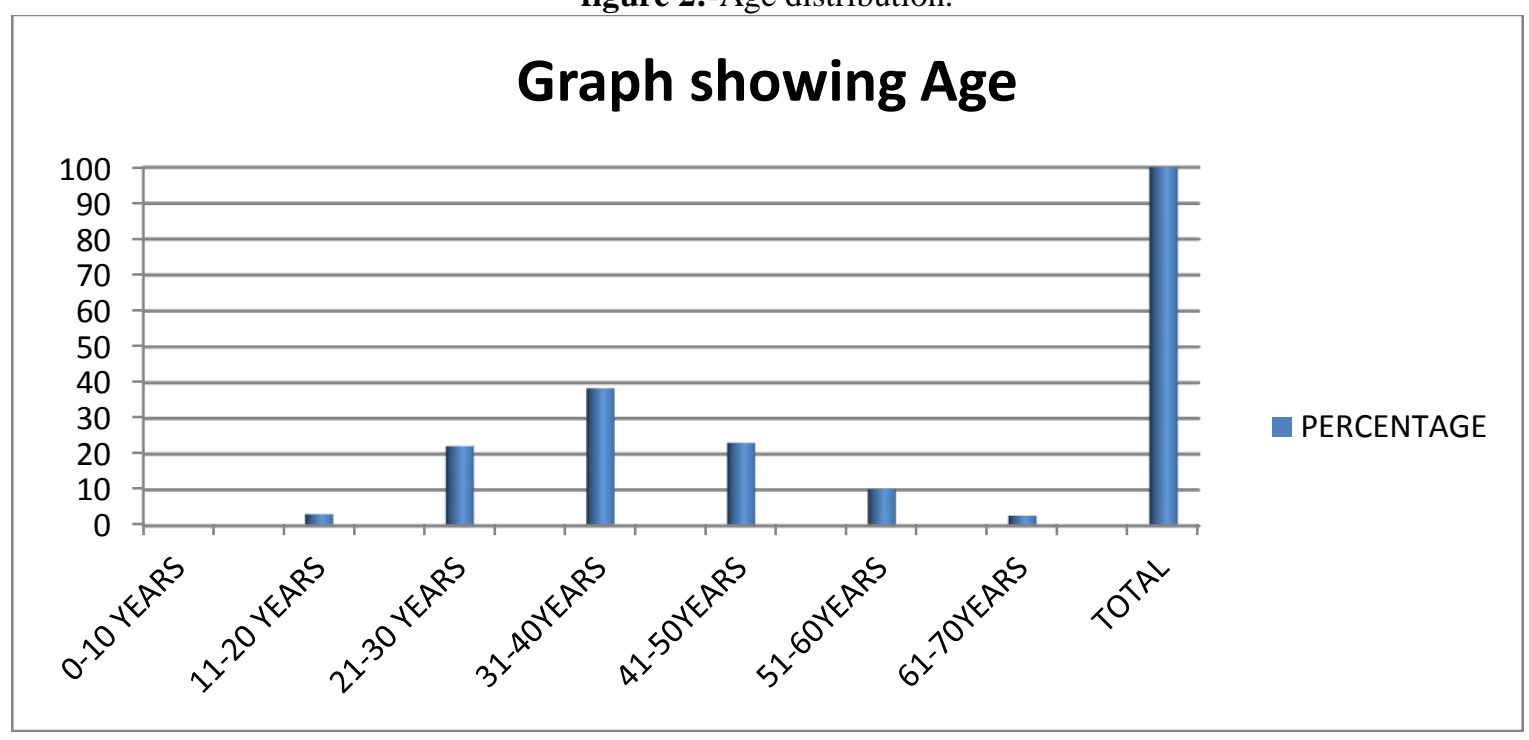

Table 2:-Gender distribution

\begin{tabular}{|l|c|c|}
\hline SEX & FREQUENCY & PERCENTAGE \\
\hline MALE & 198 & 69.7 \\
\hline FEMALE & 86 & 30.3 \\
\hline TOTAL & 284 & 100 \\
\hline
\end{tabular}

Figure 3:-Gender distribution

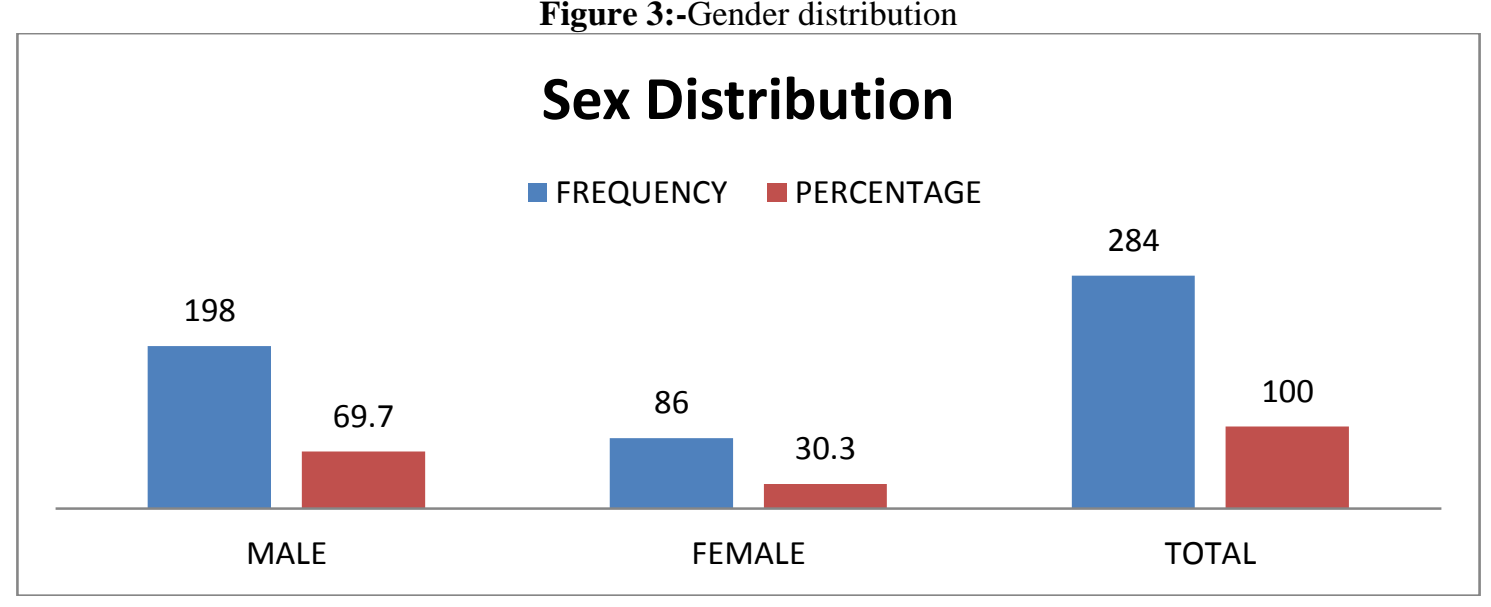

Table 3:-Ward distribution

\begin{tabular}{|l|l|l|}
\hline WARDS & FREQUENCY & PERCENATGE \\
\hline DENTAL & 12 & 4.2 \\
\hline MEDICINE & 145 & 51.5 \\
\hline NEPHRO & 16 & 5.6 \\
\hline OBG & 48 & 16.9 \\
\hline SKIN & 28 & 9.9 \\
\hline SURGERY & 35 & 12.3 \\
\hline TOTAL & 284 & 100 \\
\hline
\end{tabular}


Figure 4:-Ward distribution

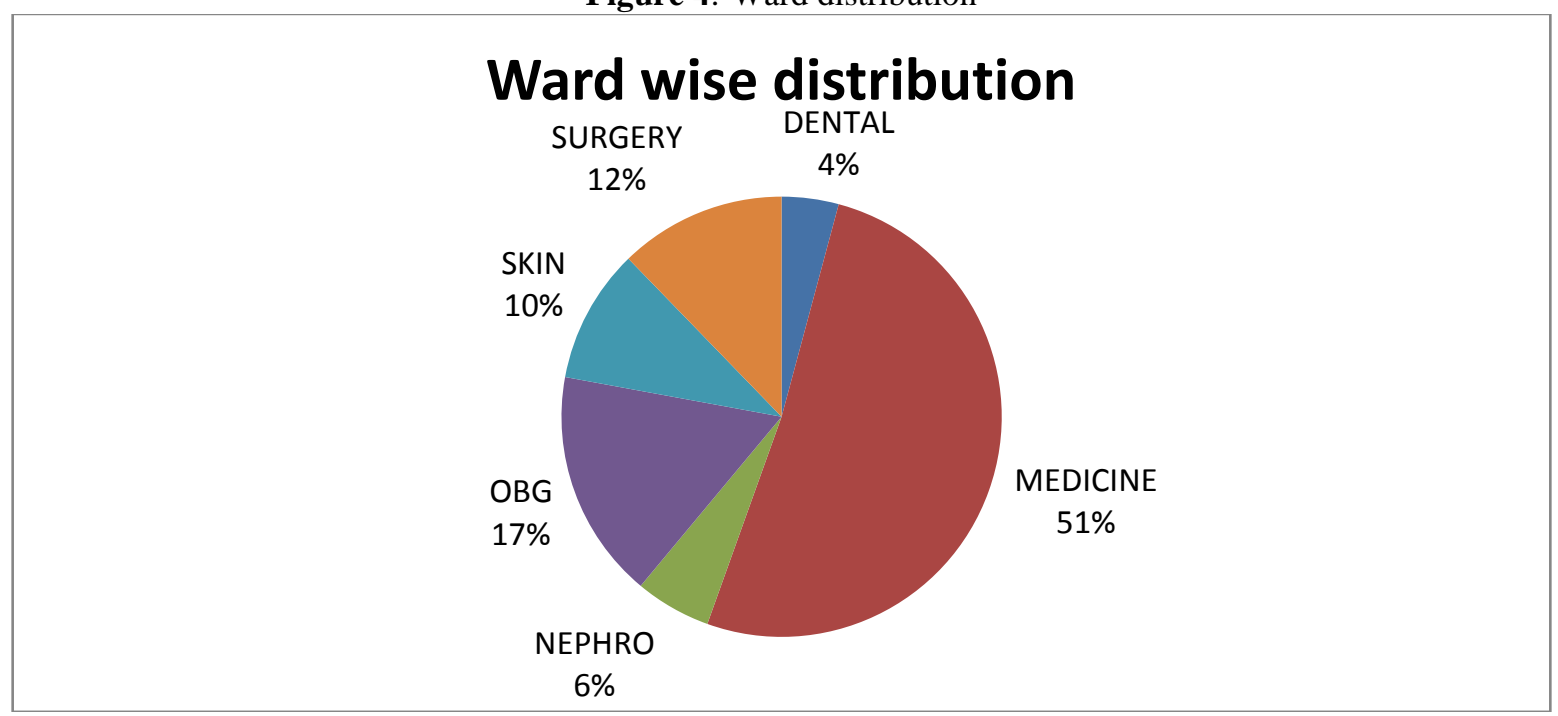

Table 4:-Risk Factors

\begin{tabular}{|l|c|c|}
\hline RISK FACTORS & FREQUENCY & PERCENTAGE \\
\hline 1.Surgery & & 5.6 \\
\hline Abscess Drainage & 16 & 35.6 \\
\hline 2.Parenteral Route & & 3.9 \\
\hline Blood transfusion & 101 & 4.2 \\
\hline Ear piercing & 11 & 3.5 \\
\hline Haemodialysis & 12 & 12.7 \\
\hline Nose piercing & 10 & 12.0 \\
\hline Tattoo & 36 & 16.9 \\
\hline 3.STD s & & 5.6 \\
\hline Genital lesions and Ulcers & 34 & 100 \\
\hline 4.Unknown History & 48 & \\
\hline 5.Others-Oral implant & 16 & 28 \\
\hline Total & 284 & \\
\hline
\end{tabular}

Figure 5: Risk factor

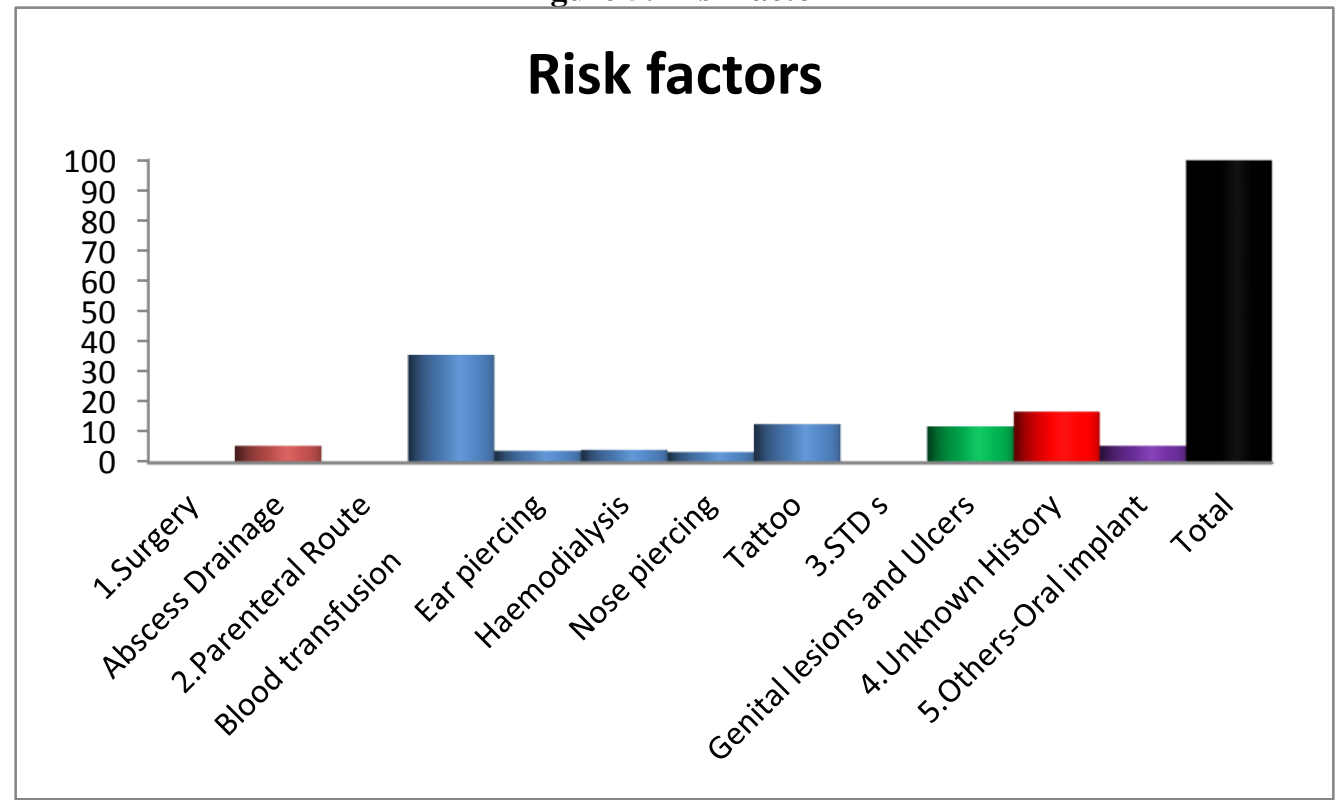




\section{Discussion:- \\ Seropositivity}

The seroprevalence of Hepatitis B infection in our study was $6 \%$. This may not necessarily represent the endemicity, magnitude in this part of the state, as ours is a tertiary care centre and significant no. of samples were from clinically suspected cases. The prevalence of Chronic HBV infection in different studies ranged from 2 to 10\% (below 8\%) as per literature survey. Therefore India has intermediate to high endemicity ${ }^{6}$

PragatiAbhimanyuBullee et al ${ }^{7}$ in Yavatmal (Maharashtra), India found that the Seroprevalence of HBsAg positive was $1.57 \%$ while in healthy donors it was $0.87 \%$. The prevalence of HBsAg in the general population of Asia, Africa, Southern Europe and South America ranges from 2\% to 20\%.HBsAgseropositivity of 3-4\% is reported in the Indian population.

There is wide variation in the prevalence in different regions of the country with the highest prevalence in Andaman and Arunachal Pradesh ${ }^{8}$.Various studies across India reports HBsAgseroprevalence ranging from $1.6 \%$ to $5.7 \%$ in South India,3-6\% in North India, and 2.97\% in West Bengal. ${ }^{9}$

The HBV seropositivity in our study was high in male (69.7\%)as compared to female(30.3\%)similar results were observed in another study conducted by AtulRukadikaret al, they found that seropositivity was high in male i.e., $73.39 \%$ than female $26.60 \% .^{10}$

This could be due to greater exposure of male patients to the health care set up.Most of the patients infected with Hepatits B were in the age group of 31 to 50 years in our study, similar results were seen in study conducted by Prasad Bhate et al.$^{11}$

\section{Risk Factors}

Parenteral route including blood transfusion and contact with infected persons is the significant risk factor for HBV transmission.Sujatha. $\mathrm{R}^{12}$ et al conducted a study ina tertiary care centre Kanpur and observed that history of contact with infected persons was $41 \%$ and Blood transfusion $14 \%$.In our study conducted in a tertiary care hospital, the professional blood donors and unsafe injections practice constitutes major high risk group for HBV infection and also showed the predominance of blood transfusion $35.6 \%$, probable sexual route of transmission $12.0 \%$ as high risk factors for HBV transmission.

Recently increased tattooing trend in both urban and rural population has been commonly associated with increased risk of HBV transmission, it was shown in cross sectional study conducted by Prasad Bhate et al,17.6\% patients were found to be infected due to tattooing, similar result were observed in our study i.e., $12.7 \%$.This shows that Tattooing is one of the significant preventable risk factors of HBV transmission, it can be prevented by public awareness, health education,specific protection,early diagnosis and treatment.

Body piercing including nose and ear piercing has become a universal fashion and in urban areas its more of fashion whereas in rural areas its a customary trend.But because of lack of sterilization of the instruments used it has contributed to theanother most important risk factor for HBV transmission.

In Eastern India, Bhagirathi Dwibediet al found that out of 712 cases, 122 were HBsAg Positive i.e., (17.1\%) with risk factors of body piercing including nose and ear piercing ${ }^{13}$

India being a highly populated country, most of the people suffer from skin infections like abscess, boils, furuncles, cyst etc. due to lack of cleanliness and hygiene, close contact and these people visit quacks for the low cost of treatment and are prone for various minor surgical procedure related infections. Sidra et al observed that around 37\% of persons were infected by minor surgical procedures whereas in our study we found that only $5.6 \%$ subjects were infected by minor surgical infections. ${ }^{14}$

Haemodailysis is the most advised treatment for impaired renal function, due to chronic kidney disease, diabetic nephropathyetc.It is an expensivetreatment modality and requires multiple visits and not affordable by all, patients opt for lower and cheaper centres for dialysis where they may contract HBV infectionby usage of old needles or not changing of membrane used in Haemodialysis unit.RubinaMalhotraet al conducted a retrospective study and found 
that $1.5 \%$ patients were found to be positive for HBsAg in patient on dialysis ${ }^{15}$. PankajPuriet alconcluded that the prevalence of $\mathrm{HBV}$ infection amongst dialysis patients in India varies from 5 to $13 \%{ }^{16}$

\section{Conclusion:-}

The present cross sectional study titled "High Seroprevalence of hepatitis-B virus infection and associated risk factors in teaching hospital of Karnataka" was undertaken in the Department of Microbiology, spanning over one year duration showed a seropositivity of $6 \%$ in patients attending this tertiary care centre.

Predominant risk factor was found to be Blood transfusion followed by, patients having genital ulcers leading to a probable association with sexual transmission. The other risk factors were exposure to major and minor surgical procedure, haemodialysis, tattoo, oral implant, Nose and Ear piercing. Prevention strategies must be targeted towards this population of patients.

Stringent blood banking laws need to be introduced. It is important to screen the blood donors to control the spread of HBV infection. The latest specific measure is the introduction of viral nucleic acid amplification test (NAAT). NAAT screening is currently in use in most of the developed countries but not yet mandatory in India. It detects viral genes rather than antibodies or antigens. NAAT will enable earlier detection of HBV.

The complexity and uncertainty related to the geographical distribution of HBV infection and chronic hepatitis B, determination of its associated risk factors, and evaluation of co-factors that accelerate its progression, underscore the difficulties in global prevention and control of HBV. Because there is lack of awareness and health education, negligence, the focus of primary prevention efforts should be safer blood supply in the developing world, safe injection practices in health care and other settings, and decreasing the number of people who initiate injection drug use.

Further studies need to be done on genotyping of large number of sample in order to determine the association with disease severity, progression and risk factor.

\section{References:-}

1. Bennett JE, Dolin R, Blaser MJ. Mandell, Douglas, and Bennett's Principles and practice of infectious diseases. Elsevier Health Sciences; 2014 Aug 28.

2. Tille P. Bailey \& Scott's diagnostic microbiology. Elsevier Health Sciences; 2013 Aug 13.

3. Kumar P, Clark ML. Kumar and Clark's clinical medicine. Elsevier Health Sciences; 2016 Jun 29.

4. Jazayeri SM, Alavian SM, Carman WF. Hepatitis B virus: origin and evolution. Journal of viral hepatitis. 2010 Apr 1;17(4):229-35.

5. K George Mathew and Praveen agarwal. Medicine Prep manual for undergraduates. $5^{\text {th }}$ edition. Elseviers. 2015.

6. WHO guidelines of Infectious Diseases. 2014, August.

7. Bulle PA, Tekam S, Gedam DS, Gujar V, Deshmukh D. Prevalence of Hepatitis B Surface Antigen (HBsAg) Positivity among General Population in Yavatmal (Maharashtra), India. Int. J. Curr. Microbiol. App. Sci. 2016;5(7):513-7.

8. Borkakoty BJ, Mahanta J, Biswas D. Circulating genotypes of hepatitis B virus in Arunachal Pradesh. Indian Journal of Medical Research. 2008 Jan 1;127(1):65.

9. Rashmi KS, Misbah-Ul-Khair S, Ravikumar KL. Profile of Hepatitis B 'e'Antigen and Antibodies to Hepatitis B 'e'Antigen in Hepatitis B Seropositive Patients at a Tertiary Care Hospital in Bengaluru, India.

10. Chowdhury A., Santra A., Pal S., Chakravarty R., et al. Community based epidemiology study of Hepatitis B virus infection (HBV). Indian J. Gastroenterol. 200120(2): A2.

11. Bhate P, Saraf N, Parikh P, Ingle M, Phadke A, Sawant P. Cross Sectional Study Of Prevalence And Risk Factors Of Hepatitis B And Hepatitis C Infection In A Rural Village Of India. Arquivos De Gastroenterologia. 2015 Dec;52(4):321-4.

12. Sujatha.R, Nidhi Pal, Arunagiri.D\&Narendran. D. Seroprevalence and Risk Factors of Hepatitis-B Infection in Patients attending a Tertiary CareCenter in Kanpur [UP],India.International Journal of Current Medical And Applied Sciences, vol.4. Issue 3, November: 2014. PP: 98-103

13. Dwibedi B, Sabat J, Ho LM, Singh SP, Sahu P, Arora R, Kar SK. Molecular epidemiology of hepatitis B virus in primitive tribes of Odisha, eastern India. Pathogens and global health. 2014 Dec 1;108(8):362-8. 
14. Shaheen S, Nouroz F, Khan S, Noreen S. A Review on Hepatitis B Virus, its Genotypes and Risk Factors. Middle-East Journal of Scientific Research. 2015;23(6):1152-7.

15. Malhotra R, Soin D, Grover P, Galhotra S, Khutan H, Kaur N. Hepatitis B virus and hepatitis C virus coinfection in hemodialysis patients: A retrospective study from a tertiary care hospital of North India. Journal of natural science, biology, and medicine. 2016 Jan;7(1):72.

16. Puri P. Tackling the hepatitis B disease burden in India. Journal of clinical and experimental hepatology. 2014 Dec 31;4(4):312-9. 